\title{
Estrutura funcional de uma semeadora de tração humana
}

\author{
Functional structure of a human-powered seeder
}

\author{
Giusepe Stefanello ${ }^{I}$ Antônio Lilles Tavares Machado ${ }^{I I}$ Ângelo Vieira dos Reis ${ }^{I I}$ \\ Roberto Lilles Tavares Machado ${ }^{\mathrm{II}}$ César Silva de Morais ${ }^{\mathrm{III}}$
}

\section{RESUMO}

O milho e o feijão são semeados em praticamente todas as pequenas unidades familiares de produção, normalmente, em sistema convencional de cultivo. Há interesse no sistema de semeadura direta, porém não estão disponíveis semeadoras adequadas às suas necessidades. As semeadoras manuais, utilizadas por esses agricultores, inclusive para semeadura direta, possuem restrições de capacidade e de desempenho operacional, além de problemas ergonômicos. É necessário o desenvolvimento de máquinas desse porte, que garantam maior qualidade na operação de semeadura dessas culturas. O objetivo do presente trabalho foi estabelecer a estrutura funcional de uma semeadora puncionadora de tração humana para semeadura direta de milho e feijão. Foi aplicada uma metodologia sistemática, contemplando análise de especificações, identificação de restrições $e$ estabelecimento das estruturas funcionais em diagrama de blocos. Foi eleita a estrutura funcional de empurrar com um dosador $e$ múltiplos abridores de solo.

Palavras-chave: projeto de máquinas, semeadora manual, máquinas agrícolas.

\section{ABSTRACT}

Maize and beans are grown on small farms usually tillage system. There is interest in migrating to no tillage, but are not available to small planters suitable for this purpose. The portable hand seeder (saraquá), massively used by these farmers, including no tillage, have capacity and operating performance constraints, besides ergonomic problems. It is necessary to develop machines of this size, ensuring higher quality at sowing these crops and reduce the painfulness of work these farmers. The aim of this research was to establish the functional structure of a human-powered drill for direct seeding of corn and beans. A systematic design methodology was applied, covering analysis of specifications, identifying constraints and establishment of functional structures as block diagram. Functional structure with a push seed meter and multiple soil openers was chosen.

Key words: machinery design, manual seeder, agricultural machinery.

\section{INTRODUÇÃO}

A agricultura familiar, responsável pela produção de $70 \%$ do feijão e $46 \%$ do milho no Brasil, enfrenta adversidades climáticas que afetam a produtividade desses cultivos, podendo comprometer a viabilidade dessas atividades (CONAB, 2012). O sistema de semeadura direta (SSD), comparado ao sistema convencional (SC), proporciona redução dos efeitos de estiagens retendo mais água no solo e disponibilizando-a às plantas (DALMAGO et al., 2009). Apesar de utilizarem predominantemente o SC de cultivo, há interesse em adotar o SSD. No entanto, uma parcela desses agricultores utiliza exclusiva ou predominantemente a força humana e equipamentos manuais para as operações agrícolas (STORCH et al., 2004; TEIXEIRA et al., 2009; MACHADO et al., 2010). Há escassez de informações e trabalhos sobre projeto e desenvolvimento de semeadoras manuais ou à tração humana.

São poucas as semeadoras manuais com desempenho satisfatório, indicando problemas estruturais ou falhas nos mecanismos dosadores (MOLIN et al., 2001). É necessário e oportuno desenvolver melhores equipamentos, considerando

\footnotetext{
IPrograma de Pós-graduação em Sistemas de Produção Agrícola Familiar, Universidade Federal de Pelotas (UFPEL), 96010-900, Pelotas, RS, Brasil. E-mail: giusepest@gmail.com. Autor para correspondência.

IDepartamento de Engenharia Rural, Faculdade de Agronomia Eliseu Maciel, UFPEL, Pelotas, RS, Brasil.

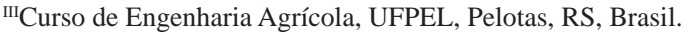


as reais necessidades desses agricultores. Para atender essa demanda, pesquisadores desenvolveram projetos de semeadoras e mecanismos de semeadura com base nessas necessidades (REIS, 2003; AREND et al., 2005; REIS \& FORCELLINI, 2006a; REIS \& FORCELLINI, 2006b; TEIXEIRA et al., 2008; STEFANELLO et al., 2010; MACHADO et al., 2010; ROMEIRO FILHO, 2012). Outros autores projetaram e testaram protótipos de semeadoras puncionadoras automatizadas (MOLIN, 2002; FRABETTI et al., 2011) e uma semeadora puncionadora de tração humana (MOLIN \& D’AGOSTINI, 1996).

No entanto, esses estudos não contemplaram projetos de semeadoras manuais ou à tração humana, utilizando metodologias de projeto sistemáticas. Dentre essas, o "Modelo de Fases" é o mais utilizado, abordando as fases de projeto informacional, conceitual, preliminar e detalhado. Neste modelo, identificam-se os clientes e suas necessidades, que são convertidas em especificações de projeto, se estabelece a estrutura funcional (EF), à qual são atribuídos princípios de solução para suas funções, sendo desenvolvida uma concepção e após define-se o leiaute do produto, materiais, processos de fabricação, montagem, componentes e documentação técnica necessária à sua produção (REIS, 2003; ROZENFELD et al., 2006; BACK et al., 2008).

Objetivou-se, neste trabalho, com uso de metodologia sistemática, obter a estrutura funcional, na forma de diagrama de blocos, de uma semeadora puncionadora de tração humana. A estrutura funcional permitirá a continuidade do desenvolvimento da semeadora, visando à semeadura direta de milho e feijão, atendendo às necessidades dos agricultores e suas restrições.

\section{MATERIAL E MÉTODOS}

A metodologia utilizada pela equipe de projeto baseou-se no Modelo de Fases, empregado com êxito no projeto de máquinas agrícolas pelo Núcleo de Desenvolvimento Integrado de Produtos da Universidade Federal de Santa Catarina (NeDIP - UFSC). O modelo tem demonstrado ao longo dos anos bons resultados no desenvolvimento de máquinas de pequeno porte destinadas à agricultura familiar (REIS, 2003; AREND et al., 2005).

Foram realizadas as duas primeiras etapas da fase de projeto conceitual (análise funcional). A primeira foi a verificação do escopo do problema, com análise das especificações de projeto e identificação de restrições. A segunda etapa foi o estabelecimento da estrutura funcional na forma de diagrama de blocos, iniciando pelo estabelecimento da função global, seguida do estabelecimento das estruturas funcionais alternativas e a escolha da melhor. Trata-se da continuidade do desenvolvimento do produto, no caso a semeadora. Para isso, foram utilizados dados e informações obtidas previamente, pela equipe de projeto, na fase informacional.

Os pontos de partida para o presente trabalho foram os requisitos dos clientes (usuários, fabricantes, revendas) valorados no diagrama de Mudge e os requisitos de projeto relacionados com os de clientes na matriz QFD (Quality Function Deployment), classificados por importância, conforme REIS (2003), REIS \& FORCELLINI (2006 ${ }^{a}$ ), REIS \& FORCELLINI (2006b) e SANTOS et al. (2008). Inicialmente, verificou-se o escopo do problema, objetivando compreendê-lo de forma abstrata, generalizando-o e eliminando-se preferências pessoais. Enfatizou-se o essencial, formulando-se a função global (FG) e o entendimento de restrições sem considerar soluções iniciais. Para estabelecer a estrutura funcional, formulou-se o problema de maneira abstrata por meio das funções da semeadora. Obteve-se a FG da máquina baseada no fluxo de material, energia e sinal e, a partir desta, desdobramentos em funções parciais (FP), auxiliares (FA) e elementares (FE). Formulouse estruturas funcionais alternativas em forma de diagrama de blocos, ferramenta fundamental para melhor adequação do projeto, sem conter nenhuma informação relativa à estrutura física do sistema.

Para escolher a estrutura funcional, foi utilizada a Matriz de Decisão que teve como critérios de seleção os requisitos de projeto e necessidades dos clientes. Os pesos dos critérios na avaliação (PR) foram o valor percentual dos requisitos de projeto no QFD e dos requisitos dos clientes no diagrama de Mudge. Na avaliação das EFs quanto ao atendimento aos requisitos, foi atribuído valor 1 para desempenho fraco, 5 para satisfatório e 10 para excelente. Para os custos do ciclo de vida, foram atribuídos valores de 1 para baixo custo, 5 para médio e 10 para alto.

\section{RESULTADOS E DISCUSSÕES}

Definiu-se que o escopo do problema consiste em aperfeiçoar as funções técnicas, proporcionando semeadura de precisão e qualidade com uma semeadora que utiliza a força muscular humana para sua tração. Transformaram-se os requisitos quantitativos relacionados diretamente com a função em requisitos qualitativos, que, por sua vez, foram generalizados para formular o seguinte 
problema: alocar as sementes no solo, proporcionando estande de plântulas adequado (população e distribuição espacial recomendados) com melhor relação benefício/custo. Ou seja, ter regularidade de distribuição longitudinal e de profundidade de deposição de sementes, além de baixa danificação das sementes, associados a um consequente aumento de produtividade com menores custos por área semeada e por tempo de operação. As restrições de projeto foram a baixa disponibilidade de força e de potência da fonte de tração e o custo de fabricação. Portanto, a semeadora deve exigir mínimo esforço físico do trabalhador e apresentar custo condizente com a realidade da agricultura familiar, além de ter capacidade de operar na presença de cobertura vegetal e em solos adensados ou compactados. A partir dessas restrições, foi definido, pela equipe de projeto, que a semeadora deve ser puncionadora, sem sulcadores, pois a realização de sulcos é restritiva à utilização da força muscular humana para sua tração.

A função global, representada pelas entradas e saídas de material, energia e sinal em relação a um sistema periférico que delimita a fronteira entre a máquina e suas interfaces (ambiente e usuário), foi definida como: semear com precisão e qualidade. Durante a semeadura, o material (sementes e solo) é progressivamente modificado através dos diversos subsistemas da máquina que interagem com o ambiente e o usuário até que a operação seja concluída. A partir da FG, identificaram-se as funções "F1 Abrir solo", "F2 Dosar sementes” e "F3 Acondicionar sementes no solo". Essas funções foram decompostas em "F1.1 Penetrar o solo", "F1.2 Controlar profundidade”, "F1.3 Afastar o solo”, "F2.1 Captar sementes”, "F2.2 Conduzir sementes”, "F2.3 Ejetar sementes”, "F3.1 Direcionar sementes”, "F3.2 Cobrir sementes” e "F3.3 Pressionar solo".

Combinando-se os fatores forma de condução e/ou acionamento (portátil ou de empurrar), número de puncionadores (um ou múltiplos) e de dosadores (um ou múltiplos), obtevese oito configurações. Na avaliação, as configurações portáteis com mais de um dosador ou mais de um abridor de solo foram descartadas devido à maior complexidade e massa para essa categoria. As configurações de empurrar com apenas um abridor de solo foram excluídas, devido à complexidade para seu funcionamento, dependendo de transformações e associação de movimentos (rotação/translação) para operar com espaçamentos longitudinais adequados. As três configurações julgadas passíveis de utilização, devido à maior viabilidade funcional, foram denominadas de estruturas A, B e C. A estrutura
“A” refere-se à configuração portátil, com um abridor de solo e um mecanismo dosador. A estrutura B é operada empurrando-se a máquina, que possui um dosador e múltiplos puncionadores. A estrutura C é de empurrar, com múltiplos dosadores e um puncionador para cada dosador.

Foram determinadas as funções auxiliares necessárias para o funcionamento da semeadora, bem como as funções elementares, completando o fluxo de sinal, energia e material. Por haver disponibilidade de dosadores de sementes utilizáveis ou adaptáveis ao projeto da semeadora, a subfunção dosar sementes é apresentada sem desdobramentos. Para vincular fisicamente os mecanismos entre si e com a fonte de tração (homem), foi utilizada a função F4, desdobrada em "F4.1 Acoplar fonte de tração" e "F4.2 Suportar mecanismos". Para acionar os mecanismos ou partes móveis, foram geradas as funções "F5.1 Captar movimento" e "F5.2 Transmitir movimento”, podendo haver associação, modificação ou transformação desse movimento. Para fornecer sementes ao dosador, foram estabelecidas as funções "F6.1 Armazenar sementes" e "F6.2 Direcionar sementes". Foram estabelecidas as funções de regulagem (F7) de dosagem, cobrimento de sementes com solo e pressão sobre o solo. Para possibilitar o transporte e manobras no final das linhas de semeadura, utilizou-se a função "F8 Sustentar para transporte”.

As estruturas diferem basicamente em multiplicidade de algumas funções e distintos fluxos de material, energia e sinal. A estrutura "A" demonstra dificuldade em associar as funções "F3.2 Cobrir sementes" e "F3.3 Pressionar solo" ao movimento alternativo imposto pela portabilidade da máquina. Enquanto há o movimento ascendente, deve haver outro movimento descendente ou de avanço para realizar essas funções. Essa dificuldade ocorre em função dessas funções acontecerem obrigatoriamente em série (em instantes diferentes). Nessa estrutura, a função F8 é idêntica à função F4.1, pois o acoplamento com a fonte de tração (homem) contempla ao mesmo tempo a sustentação para transporte.

A estrutura "B" apresenta, devido à multiplicidade de abridores de solo, maior número das funções F1.1, F1.3 e F3.1. No entanto, em relação à estrutura “A”, possibilita maior capacidade operacional e facilidade de operação, dado o seu modo de condução, permitindo ainda o acoplamento de cobridores de sementes e compactadores de solo em posição posterior ao ponto de liberação das sementes. Isso faz com que a dificuldade apresentada na estrutura " $A$ " não seja evidenciada nessa estrutura, pois as funções F3.2 e F3.3 ocorrem naturalmente em sequência. 
A estrutura "C” apresenta multiplicidade das funções F6.2, F2 e F1.1 e F1.3, apresentando as vantagens da estrutura "B", mas com o inconveniente de aumentar o número de dosadores. Associada a isso, há a sobreposição de chances de ocorrência de falhas desse mecanismo, relacionadas à confiabilidade do sistema, e maior número de ajustes e regulagens.

Com relação à massa total, a estrutura “A”, por ser do tipo portátil, é tecnicamente inferior às configurações de empurrar, que permitem conduzir maior massa. Quanto à precisão de semeadura, as estruturas " $B$ " e " $C$ " são tecnicamente superiores em função de sua automatização, não dependendo da habilidade do operador. A facilidade de transporte da estrutura “A” deve-se à sua menor massa, em função do número reduzido de componentes, contribuindo também para os baixos custos de fabricação e manutenção. Isso não ocorre com o custo operacional, visto que a capacidade operacional, diretamente relacionada a esse custo, é inferior à das demais estruturas.

Após aplicação da Matriz de Decisão (Tabela 1) e avaliação de custos, a estrutura “A” obteve o menor índice de custo (IC), enquanto a estrutura "C" apresentou o maior. No entanto, apesar de seu IC ser 36\% maior que o da estrutura " $A$ ", a estrutura "B" obteve as melhores avaliações quanto aos critérios técnicos (IDT) e relação IDT/IC, indicando que essa deve ser utilizada para a continuidade do projeto (Figura 1). Dentre os critérios técnicos (Tabela 1), destacam-se os relacionados aos aspectos funcionais por sua vez associados à qualidade de semeadura (distribuição longitudinal, regularidade de profundidade e danificação de sementes). Também foram determinantes a vida útil, a massa total e a duração da regulagem. Apesar da similaridade com as funções das semeadoras encontradas no mercado, o que diferencia as máquinas, dentro do mesmo paradigma tecnológico, é o seu arranjo estrutural (determinado pela estrutura funcional) e os princípios de solução empregados para cada subfunção.

As estruturas funcionais obtidas se assemelham em parte à utilizada por REIS \& FORCELLINI (2002) no julgamento de concepções de semeadoras de tração mecânica, com fluxo idêntico de materiais, mas diferindo no pequeno número de funções auxiliares. No presente trabalho, essas estruturas foram mais detalhadas, sendo complementadas todas as funções auxiliares e elementares necessárias para a operação de semeadura.

Em projeto de dispositivo para semeadura e deposição de sementes graúdas para semeadoras de pequeno porte, STEFANELLO et al. (2010) optaram por uma estrutura funcional semelhante, em parte, às obtidas no presente trabalho, pois referia-se a um

Tabela 1 - Matriz de decisão para escolha da estrutura funcional da semeadora.

\begin{tabular}{|c|c|c|c|c|}
\hline & & A & B & $\mathrm{C}$ \\
\hline Critérios técnicos (requisitos e necessidades) & PR & \multicolumn{3}{|c|}{-----------------------Avaliação do atendimento----------------------- } \\
\hline Regularidade distribuição longitudinal semente & 16,71 & 1 & 10 & 10 \\
\hline Regularidade profundidade deposição semente & 10,43 & 1 & 10 & 10 \\
\hline Danificação das sementes & 8,67 & 5 & 10 & 5 \\
\hline Intervalo entre manutenções & 7,54 & 5 & 5 & 1 \\
\hline Massa total & 6,41 & 1 & 10 & 5 \\
\hline Duração da regulagem & 6,41 & 5 & 10 & 1 \\
\hline Processos de fabricação usuais & 5,28 & 10 & 5 & 5 \\
\hline Duração da manutenção & 5,15 & 10 & 5 & 1 \\
\hline Montagens manuais & 4,27 & 10 & 5 & 5 \\
\hline Materiais padronizados comuns & 4,27 & 10 & 10 & 10 \\
\hline Vida útil & 4,02 & 5 & 10 & 5 \\
\hline Ser fácil de transportar & 2,40 & 10 & 5 & 5 \\
\hline Requisitos de projeto não utilizados no QFD & 2,40 & 5,6 & 7,3 & 6,6 \\
\hline Índice de desempenho técnico (IDT) & & 393,93 & 709,94 & 504,33 \\
\hline Custo de fabricação & 14,82 & 1 & 5 & 10 \\
\hline Custo de manutenção & 6,03 & 1 & 5 & 10 \\
\hline Custo de operação (não utilizado no QFD) & 6,03 & 10 & 1 & 1 \\
\hline Índice de custo (IC) & & 81,15 & 110,28 & 214,53 \\
\hline Relação entre IDT e IC & & 4,85 & 6,44 & 2,35 \\
\hline
\end{tabular}




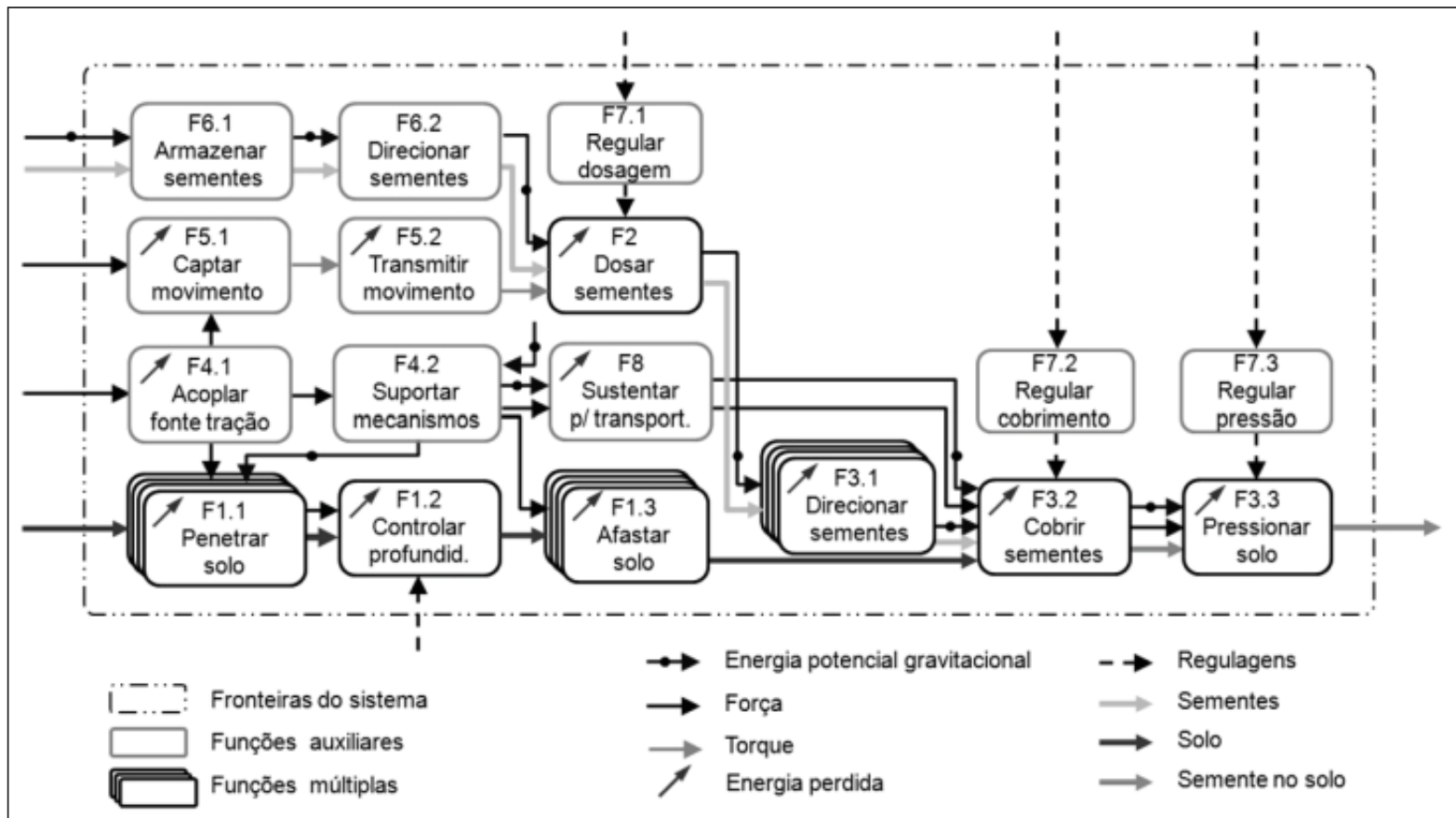

Figura 1 - Estrutura funcional B: representação do fluxo de material, energia e sinal da configuração de uma semeadora puncionadora de empurrar com um dosador e múltiplos puncionadores.

subsistema da semeadora. As diferenças da EF dos autores estão no maior desdobramento da função dosar e depositar sementes e ausência de algumas funções. Também há diferença no fluxo de material, pois, na EF obtida pelos autores, não há interação dos materiais solo e sementes (não há fluxo simultâneo em nenhum dos blocos), visto que há apenas dosagem e deposição das sementes no solo. Essa interação é demonstrada na EF "B", escolhida no presente trabalho, nos blocos com as subfunções relativas ao cobrimento e compactação do solo sobre a semente.

No projeto de uma semeadora de sementes graúdas para agricultura de base familiar e ecológica, foram desenvolvidas estruturas funcionais para tração animal e mecânica de duas linhas (TEIXEIRA, 2008; MACHADO et al., 2010). As semelhanças dessa em relação à estrutura escolhida no presente trabalho são os fluxos de material e as diferenças são a presença das funções: "Posicionar usuário na operação"; "Regular espaçamento entre linhas”; "Ligar desligar/dosador”; e "Cortar palha". Essas alterações ocorreram em função do presente trabalho ser de uma semeadora puncionadora de tração humana, dispensando algumas funções necessárias à semeadora projetada pelos autores.

Não foi possível comparar a estrutura funcional do trabalho com as dos demais projetos e estudos citados. Isso ocorre por não apresentarem estruturas funcionais em diagramas de blocos, devido à utilização de outras metodologias de projeto.

\section{CONCLUSÃO}

Foi possível estabelecer a estrutura funcional "B", semeadora puncionadora de tração humana de empurrar, configurada com um dosador e múltiplos abridores de solo. A estrutura funcional "B" é a mais adequada para continuidade do projeto.

\section{AGRADECIMENTOS}

À Coordenação de Aperfeiçoamento de Pessoal de Nível Superior (CAPES), pela concessão da bolsa de mestrado ao primeiro autor e ao Conselho Nacional de Desenvolvimento Científico e Tecnológico (CNPq), Edital MCT/CNPq/MDA/SAF/ Dater $n^{0} 033 / 2009$, pelo financiamento do projeto.

\section{REFERÊNCIAS}

AREND, L. et al. Desenvolvimento e testes de uma semeadoraadubadora modular para pequenas propriedades rurais. Engenharia Agrícola, Jaboticabal, v.25, p.801-808, 2005. Disponível em: <http://www.scielo.br/pdf/eagri/v25n3/28077.pdf>. Acesso em; 7 jan. 2013. doi: 10.1590/S0100-69162005000300027.

BACK, N. et al. Projeto integrado de produtos: planejamento, concepção e modelagem. Barueri: Manole, 2008. 601p.

CONAB (COMPANHIA NACIONAL DE ABASTECIMENTO). Acompanhamento da safra brasileira de grãos 2011/12 - oitavo levantamento, maio/2012. Brasília, 2012. 36p.

Ciência Rural, v.44, n.9, set, 2014. 
DALMAGO, G.A. et al. Retenção e disponibilidade de água às plantas, em solo sob plantio direto e preparo convencional. Revista Brasileira de Engenharia Agrícola e Ambiental, Campina Grande, v.13, supl., p.855-864, 2009. Disponível em: <http://www.scielo.br/pdf/rbeaa/v13s0/v13s0a07.pdf>. Acesso em: 7 jan. 2013. doi: 10.1590/S1415-43662009000700007.

FRABETTI, D.R. et al. Desenvolvimento e avaliação do desempenho de uma semeadora puncionadora para plantio direto de milho. Revista Brasileira de Engenharia Agrícola e Ambiental, Campina Grande, v.15, n.2, p.199-204, 2011. Disponível em: <http://www.scielo.br/pdf/rbeaa/v15n2/v15n02a13.pdf>. Acesso em: 7 jan. 2013. doi: 10.1590/S1415-43662011000200013.

MACHADO, A.L.T. et al. Projeto conceitual de uma semeadora para a agricultura de base ecológica do Rio Grande do Sul. In: CONGRESO INTERNACIONAL DE INGENIERÍAAGRÍCOLA, 6., 2010, Chillán. Anais... Chillán: UC, 2010. p.1-12.

MOLIN, J.P. A punch planter with adjustable seed spacing. In: ASAE ANNUAL INTERNATIONAL MEETING / CIGR WORLD CONGRESS, 15., 2002, Chicago, Illinois, USA. Anais... St. Joseph, Michigan: ASAE, 2002. p.1-8.

MOLIN, J.P.; D’AGOSTINI, V. Development of a rolling punch planter for stony soil conditions. Agricultural Mechanization in Asia, Africa and Latin America, Tokyo, v.27, n.3, p.17-19, 1996.

MOLIN, J.P. et al. Avaliação do desempenho de semeadoras manuais. Revista Brasileira de Engenharia Agrícola e Ambiental, Campina Grande, PB, v.5, n.2, p.339-343, 2001. Disponível em: <http://www.scielo.br/pdf/rbeaa/v5n2/v5n2a27.pdf>. Acesso em: 7 jan. 2013. doi: 10.1590/S1415-43662001000200027.

REIS, Â.V. dos; FORCELLINI, F.A. Functional analysis in the evaluation of four concepts of planters. Ciência Rural, Santa Maria, v.32, n.6, p.969-975, 2002. Disponível em: <http://www. scielo.br/pdf/cr/v32n6/12741.pdf>. Acesso em: 7 jan. 2013. doi: 10.1590/S0103-84782002000600009.

REIS, A.V dos. Desenvolvimento de concepções para dosagem e deposição de precisão para sementes miúdas. 2003. $277 f$. Tese (Doutorado em Engenharia Mecânica) - Centro Tecnológico, Universidade Federal de Santa Catarina, Florianópolis, SC.

REIS, Â.V. dos; FORCELLINI, F.A. Identificação de requisitos de clientes para o projeto de um dosador de precisão para sementes miúdas. Engenharia Agrícola, Jaboticabal, v.26, n.1, p.309302, 2006a. Disponível em: <http://www.scielo.br/pdf/eagri/ v26n1/30122.pdf>. Acesso em: 7 jan. 2013. doi: 10.1590/S010069162006000100033.

REIS, Â.V. dos; FORCELLINI, F.A. Obtenção de especificações para o projeto de um mecanismo dosador de precisão para sementes miúdas. Engenharia Rural, Piracicaba, v.17, n.1, p.47-57, 2006 b.

ROMEIRO FILHO, E. Uma abordagem centrada no usuário para o projeto de máquinas agrícolas de tração animal. Gestão \& Produção, São Carlos, v.19, n.1, p.93-102, 2012. Disponível em: $<$ http://www.scielo.br/pdf/gp/v19n1/a07v19n1.pdf>. Acesso em: 7 jan. 2013. doi: 10.1590/S0104-530X2012000100007.

ROZENFELD, H. et al. Gestão de desenvolvimento de produtos: uma referência para a melhoria do processo. São Paulo: Saraiva, 2006. 542p.

SANTOS, P.M. dos et al. Prioridades de requisitos para projeto de postos de operação de tratores quanto à ergonomia e segurança. Pesquisa Agropecuária Brasileira, Brasília, v.43, n.7, p.869-877, 2008.

STEFANELLO, G. et al. Desenvolvimento de mecanismo dosador-depositor rotativo de sementes graúdas para agricultura familiar. In: CONGRESO INTERNACIONAL DE INGENIERÍA AGRÍCOLA, 6., 2010, Chillán. Anais... Chillán: UC, 2010. p.1-16.

STORCH, G. et al. Caracterização de um grupo de produtores agroecológicos do sul do RS. Revista Brasileira de Agrociência, Pelotas, v.10, n.3, p.357-362, 2004. Disponível em: <http://www. ufpel.tche.br/faem/agrociencia/v10n3/artigo16.pdf>. Acesso em: 7 jan. 2013.

TEIXEIRA, S.S. et al. Caracterização da produção agroecológica do sul do Rio Grande do Sul e sua relação com a mecanização agrícola. Engenharia Agrícola, Jaboticabal, v.29, n.1, p.162-171, 2009. Disponível em: <http://www.scielo.br/pdf/eagri/v29n1/ a16v29n1.pdf $>$. Acesso em: 7 jan. 2013. doi: 10.1590/S010069162009000100016.

TEIXEIRA, S.S. Projeto conceitual de uma semeadora de milho e feijão voltada para a agricultura familiar de base ecológica. 2008. 113f. Dissertação (Mestrado em Ciências) - Universidade Federal de Pelotas, Pelotas, RS. 